\title{
Using a virtual machine environment for developing, testing, and training for the UM-UKCA composition-climate model, using Unified Model version 10.9 and above
}

\author{
Nathan Luke Abraham ${ }^{1,2}$, Alexander T. Archibald ${ }^{1,2}$, Paul Cresswell ${ }^{3}$, Sam Cusworth ${ }^{3}$, Mohit Dalvi ${ }^{3}$, \\ David Matthews ${ }^{3}$, Steven Wardle ${ }^{3}$, and Stuart Whitehouse ${ }^{3}$ \\ ${ }^{1}$ Department of Chemistry, University of Cambridge, Cambridge, CB2 1EW, UK \\ ${ }^{2}$ National Centre for Atmospheric Science, UK \\ ${ }^{3}$ Met Office, FitzRoy Road, Exeter, EX1 3PB, UK
}

Correspondence: Nathan Luke Abraham (luke.abraham@atm.ch.cam.ac.uk)

Received: 8 May 2018 - Discussion started: 18 May 2018

Revised: 10 August 2018 - Accepted: 23 August 2018 - Published: 6 September 2018

\begin{abstract}
The Met Office Unified Model (UM) is a state-ofthe-art weather and climate model that is used operationally worldwide. UKCA is the chemistry and aerosol sub model of the UM that enables interactive composition and physical atmosphere interactions, but which adds an additional 120000 lines of code to the model. Ensuring that the UM code and UM-UKCA (the UM running with interactive chemistry and aerosols) is well tested is thus essential. While a comprehensive test harness is in place at the Met Office and partner sites to aid in development, this is not available to many UM users. Recently, the Met Office have made available a virtual machine environment that can be used to run the UM on a desktop or laptop PC. Here we describe the development of a UM-UKCA configuration that is able to run within this virtual machine while only needing $6 \mathrm{~GB}$ of memory, before discussing the applications of this system for model development, testing, and training.
\end{abstract}

Copyright statement. The works published in this journal are distributed under the Creative Commons Attribution 4.0 License. This license does not affect the Crown copyright work, which is re-usable under the Open Government Licence (OGL). The Creative Commons Attribution 4.0 License and the OGL are interoperable and do not conflict with, reduce, or limit each other.

(C) Crown copyright 2018

\section{Introduction}

The Met Office Unified Model (UM; Cullen, 1993) is a state of the art general circulation model, that is used operationally worldwide for weather forecasts and climate projections. The UM comprises of over 965000 lines of computer code, mainly written in Fortran 90/95. A comprehensive test harness is in place at the Met Office and some partner sites such as Australia, New Zealand, South Korea, Poland, and elsewhere, to aid in development and to ensure that the code is well-tested, which is comprehensive but labour intensive to maintain. There are over 450 UM developers, and this testing system is not available to many of those that do not work at the Met Office. There are three UM releases per year, and code must be tested as part of the standard code development process. The UM code itself is hosted at the Met Office Science Repository Service (UK Met Office, 2018b), which is accessible to all users.

Recently the Met Office have provided a virtual machine (VM) configuration that can be used to run the UM on a desktop or laptop PC (Matthews et al., 2018). A VM is essentially an emulation of a complete and self-contained computer (or "guest"), running as software within another computer (or "host") which virtualises the hardware that the guest operating system is installed on. A similar system is a container, which will only include the software stack required to execute a program that is then portable between different computers without needing a complex compile and install process. These virtual environments are useful when 
using large and complex computer models as they are standardised and consistent between different host platforms, although changes to the underlying hardware means that results may not be identical between simulations on two different hosts using otherwise identical guest machines. As the environments are consistent and repeatable, these are often useful for training.

The Weather Research and Forecasting model (WRF; Skamarock et al., 2008) has been run on both VMs and containers (Hacker et al., 2017). Due to the standardised environment that they provide, VMs are also useful to enable analysis of model data by providing a consistent platform for analysis tools that is available to all researchers, such as that provided by the Regional Climate Model Evaluation System (RCMES), which has also been used for training users of this system (Lee et al., 2018). Here we describe the implementation of the United Kingdom Chemistry and Aerosols (UKCA) composition-climate model within the Met Office VM to better facilitate development and testing of new model code, and to provide a standardised environment for training new users in how to use UM-UKCA.

\section{The Met Office Virtual Machine}

The Met Office Virtual Machine makes use of VirtualBox (Oracle, 2018) and Vagrant (HashiCorp, 2018) to provision the VM, and will automatically install the required packages that are needed to use the UM, namely FCM (Shin et al., 2017), Rose (Shin et al., 2018), and Cylc (Oliver et al., 2018). FCM is a build and version control system built around Subversion. Rose is a system for creating, editing, and running application configurations and it is used as the graphical user interface for the UM to configure the input namelists. Cylc is a workflow tool that is used to schedule the various tasks needed to run an instance of the UM in the correct sequence. With these installed it is then possible to install the UM on the VM, and this process is documented in detail in UM documentation paper X10 (Cresswell, 2018). It is also possible to install the Met Office Iris Python library (UK Met Office, 2018a) on the VM, which is used to read and process UM output files. The time taken to install everything and get the UM up and running is dependent on host machine and internet connection speed, but can be as quick as $30 \mathrm{~min}$.

Some simple UM configurations are provided that only require 2 cores and $3 \mathrm{~GB}$ of memory in total, based around low-resolution versions of the Global Atmosphere 6 (Walters et al., 2017a), limited area, or the single-column model configuration of the UM (Cullen, 1993). However, configurations using UKCA chemistry and aerosol schemes usually require much more memory due to the large number of threedimensional fields used.

For this study we use an Ubuntu 16.04LTS host with 32 Intel Xeon $2.0 \mathrm{GHz}$ cores and $64 \mathrm{~GB}$ of memory, and an Ubuntu 16.04LTS guest configured with 2, 4, 8, or 16 cores

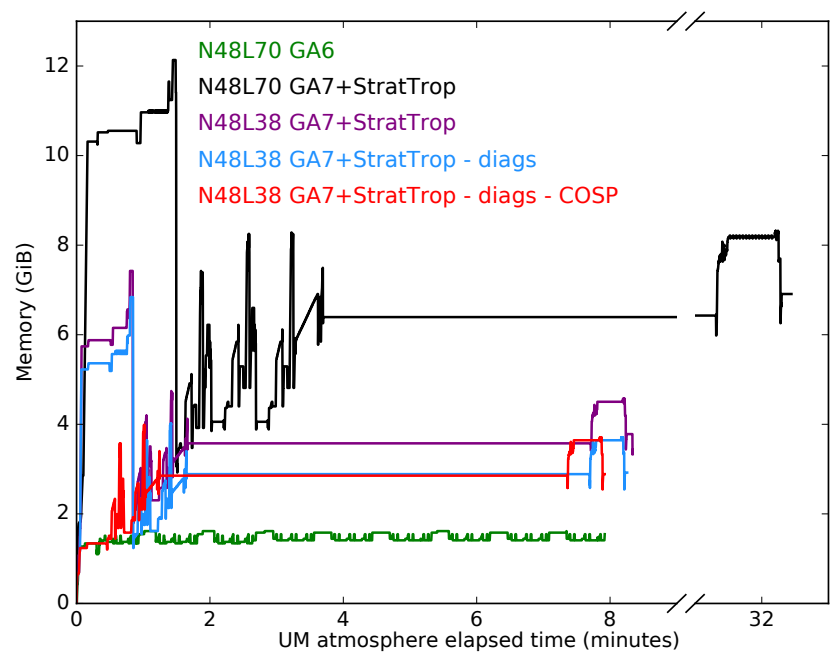

Figure 1. Memory usage of various UM configurations on the VM. Each simulation was performed using 1 MPI process without using OpenMP parallelisation. Further details of these different configurations are given in Table 1.

and up to $20 \mathrm{~GB}$ of memory as required. The Met Office VM can run a number of different guest GNU/Linux operating systems, although Ubuntu 16.04LTS is the current recommended distribution. It can also be used with GNU/Linux, macOS, and Windows hosts and will take up a maximum of $30 \mathrm{~GB}$ of hard-disk space. There is only a single user on the VM (named "vagrant"), and for simplicity the UM is installed into this user's home directory, rather than to a central location on the VM's filesystem (as would need to be done on a HPC system). Due to license restrictions, only freely available Fortran and $\mathrm{C}$ compilers can be used on the VM. The GNU gfortran and gec compilers are used as standard as they come with the guest Ubuntu distribution used by this system and have adequate feature support to compile the UM.

\section{The UM-UKCA model}

The United Kingdom Chemistry and Aerosols model is part of the Met Office Unified Model and provides a framework for adding aerosol and chemistry schemes to the UM. Aerosol microphysics is simulated by the GLOMAP-mode model (Mann et al., 2010), and this can be run with prescribed oxidant fields as in Global Atmosphere 7 (GA7; Walters et al., 2017b), or coupled interactively to the different UKCA chemistry schemes provided. The chemistry scheme used here is StratTrop (also known as CheST), which is a combination of the stratospheric chemistry scheme of Morgenstern et al. (2009) and the tropospheric chemistry scheme of O'Connor et al. (2014). This scheme has previously been used in standalone studies (Banerjee et al., 2014; Esentürk et al., 2018; Ferracci et al., 2018; Finney et al., 2016; Hardiman et al., 2017) and for the Chemistry Climate Model Initiative 
Table 1. Description of the curves presented in Fig. 1.

\begin{tabular}{|c|c|c|c|}
\hline Curve in Fig. 1 & UM resolution & Configuration details & $\begin{array}{r}\text { Peak memory usage }(\mathrm{GiB}) \\
1 \times 1 \text { MPI processes without OpenMP }\end{array}$ \\
\hline Green curve & $\begin{array}{l}\text { N48L70 } \\
3.75^{\circ} \times 2.5^{\circ} \text { with } 70 \text { verti- } \\
\text { cal levels up to } 80 \mathrm{~km}\end{array}$ & $\begin{array}{l}\text { GA6 configuration with } 27 \text { dynamical } \\
\text { timesteps ( } 20 \text { min dynamical timestep). }\end{array}$ & 1.62 \\
\hline Black curve & $\begin{array}{l}\text { N48L70 } \\
3.75^{\circ} \times 2.5^{\circ} \text { with } 70 \text { verti- } \\
\text { cal levels up to } 80 \mathrm{~km}\end{array}$ & $\begin{array}{l}\text { GA7+StratTrop configuration with } 3 \\
\text { dynamical timesteps and } 1 \text { chem- } \\
\text { ical timestep ( } 20 \text {-minute dynamical } \\
\text { timestep, } 1 \text { h chemical timestep). }\end{array}$ & 12.13 \\
\hline Purple curve & $\begin{array}{l}\text { N48L38 } \\
3.75^{\circ} \times 2.5^{\circ} \text { with } 38 \text { verti- } \\
\text { cal levels up to } 40 \mathrm{~km}\end{array}$ & $\begin{array}{l}\text { GA7+StratTrop configuration with } 2 \\
\text { dynamical timesteps and } 1 \text { chemical } \\
\text { timestep ( } 30 \text { min dynamical timestep, } \\
1 \text { h chemical timestep). }\end{array}$ & 7.43 \\
\hline Blue curve & $\begin{array}{l}\text { N48L38 } \\
3.75^{\circ} \times 2.5^{\circ} \text { with } 38 \text { verti- } \\
\text { cal levels up to } 40 \mathrm{~km}\end{array}$ & $\begin{array}{l}\text { GA7+StratTrop configuration with } 2 \\
\text { dynamical timesteps and } 1 \text { chemical } \\
\text { timestep ( } 30 \text { min dynamical timestep, } \\
1 \text { h chemical timestep). } \\
\text { Only minimal diagnostic output is in- } \\
\text { cluded. }\end{array}$ & 6.84 \\
\hline Red curve & $\begin{array}{l}\text { N48L38 } \\
3.75^{\circ} \times 2.5^{\circ} \text { with } 38 \text { verti- } \\
\text { cal levels up to } 40 \mathrm{~km}\end{array}$ & $\begin{array}{l}\text { GA7+StratTrop configuration with } 2 \\
\text { dynamical timesteps and } 1 \text { chemical } \\
\text { timestep ( } 30 \text { min dynamical timestep, } \\
1 \text { h chemical timestep). } \\
\text { Only minimal diagnostic output is in- } \\
\text { cluded and the CFMIP Observation } \\
\text { Simulator Package (COSP) has been } \\
\text { disabled. }\end{array}$ & 3.99 \\
\hline
\end{tabular}
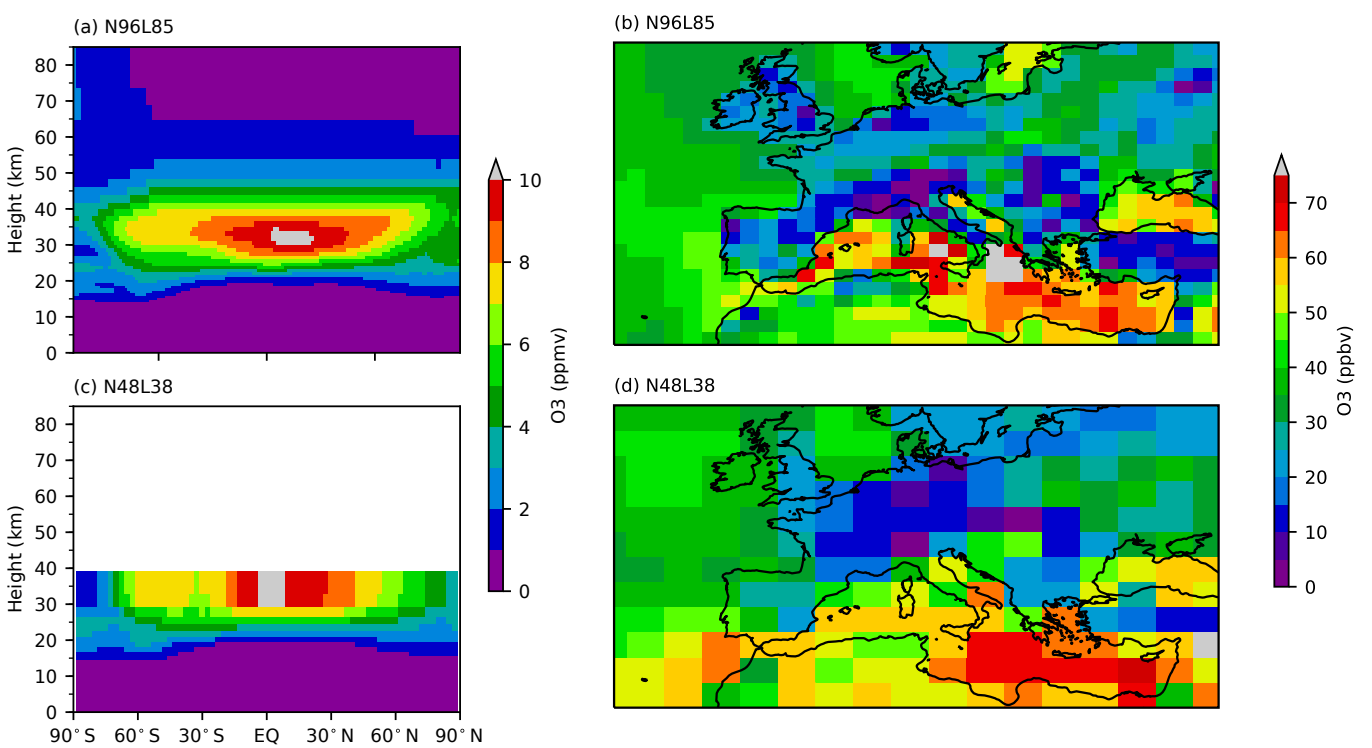

Figure 2. Comparison of modelled ozone from N96L85 and N48L38 UKCA configurations, highlighting the differences in model resolution and vertical extent. All plots are $3 \mathrm{~h}$ means from the first 3 model hours of simulation: (a, b) N96L85 UM-UKCA configuration; (c, d) N48L38 UM-UKCA configuration. 
(Morgenstern et al., 2017), and will be used in the upcoming UK Earth system model, UKESM1. A full technical description of UKCA can be found in UM documentation paper 84 (Abraham et al., 2018). UKCA makes up over $12.5 \%$ of the UM code, at just over 121000 lines.

Here we will use the StratTrop chemistry added to a GA7 configuration, which will require an additional 169 transported chemical and aerosol tracers and other 3-D fields over the GA6 configuration currently provided on the VM, along with extra diagnostics calculated at run-time. Typical climate configurations of UKCA use the so-called N96L85 model resolution, $1.875^{\circ} \times 1.25^{\circ}$ with 85 vertical levels up to $85 \mathrm{~km}$. This configuration requires around $120 \mathrm{~GB}$ of memory, and so running on a standard desktop is not feasible. However, it is possible to use a lower resolution, and turn-off highmemory sections of code, to allow a model configuration to fit within the specifications of a standard desktop, as described in Sect. 4.

\section{Developing a low memory UKCA configuration}

\subsection{Changes to the model configuration}

Figure 1 shows the development of a low-memory UKCA configuration that is suitable to be used on the VM, with further details provided in Table 1. Taking a N96L85 climate configuration based around the Global Atmosphere 7 configuration of the UM with UKCA StratTrop chemistry included, and re-gridding this to $\mathrm{N} 48 \mathrm{~L} 70\left(3.75^{\circ} \times 2.5^{\circ}\right.$ with 70 vertical levels up to $80 \mathrm{~km}$ ) allowed the required memory to be reduced to only $12 \mathrm{~GB}$. While this is a great improvement, it is still too much to allow the set-up to be used easily in a VM on a personal computer. The number of vertical levels can be reduced further to 38 (with a model top at $40 \mathrm{~km}$ ), as is used in the HadGEM2-ES configuration of the UM (Collins et al., 2011; O'Connor et al., 2014), which allows the model to only need $7.5 \mathrm{~GB}$ of memory and allows the dynamical timestep to be increased from 20 to $30 \mathrm{~min}$, also reducing the overall run-time. The memory requirements can be lowered even more by turning off diagnostics and diagnostic sections that are not required for UKCA coupling to reduce the number of large three-dimensions arrays that need to be allocated, leaving a model configuration that only needs 4 GB of memory. The other sharp peaks that are consistent between configurations are from sections such as dynamics, convection, or unavoidable calls to the diagnostics routines, and so cannot be turned off to reduce the memory requirements further.

When combined with the VM's operating system, using this $4 \mathrm{~GB}$ configuration means that it is possible to run UMUKCA with only $6 \mathrm{~GB}$ required in total. This total memory requirement increases to $8 \mathrm{~GB}$ if stricter compiler checks are used (see Sect. 5). Figure 2 compares UKCA ozone from a N96L85 climate configuration and from the low-memory N48L38 configuration that can be used on the VM. Here both models were run for 3 model hours, with output provided as a mean over this period.

\subsection{Comparison to HPC implementation}

Within the UK, academic researchers who use the UM have access to at least two supercomputers, ARCHER (a Cray XC30) and the Met Office XCS-C (a Cray XC40). Combined, these have 57168 cores and $179136 \mathrm{~GB}$ of memory available for running the UM, and are both suitable for large production runs, such as for the CMIP6 historical and DECK experiments (Eyring et al., 2016), or for AerChemMIP (Collins et al., 2017).

However, not all work involves long and large simulations. When developing a change, often what is most important is the speed of compilation and the over-all turn-around from "what changes do I need to implement?" to "the model runs successfully".

Table 2 shows very approximate timings on these three different environments (ARCHER, the XCS-C, and the VM setup described in Sect. 2) for the compile (including code extract), reconfiguration, and atmosphere tasks for the N48L38 UKCA configuration described in Sect. 4. Here we are not considering a detailed comparison of identical N48L38 UKCA configurations on different computing systems but are instead interested in the typical configuration that would be used on each system when making new code developments. Care should be taken with these results, as they are dependent on many factors that are impossible to isolate. The compile, reconfiguration, and atmosphere tasks may each use a different number of MPI processes on the three platforms, with different clock speeds and using different filesystems. Different compilers, compiler versions, and flags are used between the machines. Here the run-length has been increased to 3 model hours ( 6 dynamical timesteps or 3 chemical timesteps).

While the model run-time is fastest on the two supercomputers, when queue times are considered the VM may be a better option for model development jobs over ARCHER. More cores can also be provided to the VM if available, further reducing run-times (see Table 4).

Throughput on the XCS-C is broadly better than on ARCHER and the VM, although both of these supercomputers are large and complex, and will always have delays due to planned (and unplanned) downtime for example. As the VM is a single-user environment that can be installed on a personal computer, the whole system is simpler and less error prone as there is no waiting, no queues, no filesystem I/O contention etc. This means that, for initial developments at least, the VM environment is likely to be the easiest and fastest to use due to the immediate turnaround. 


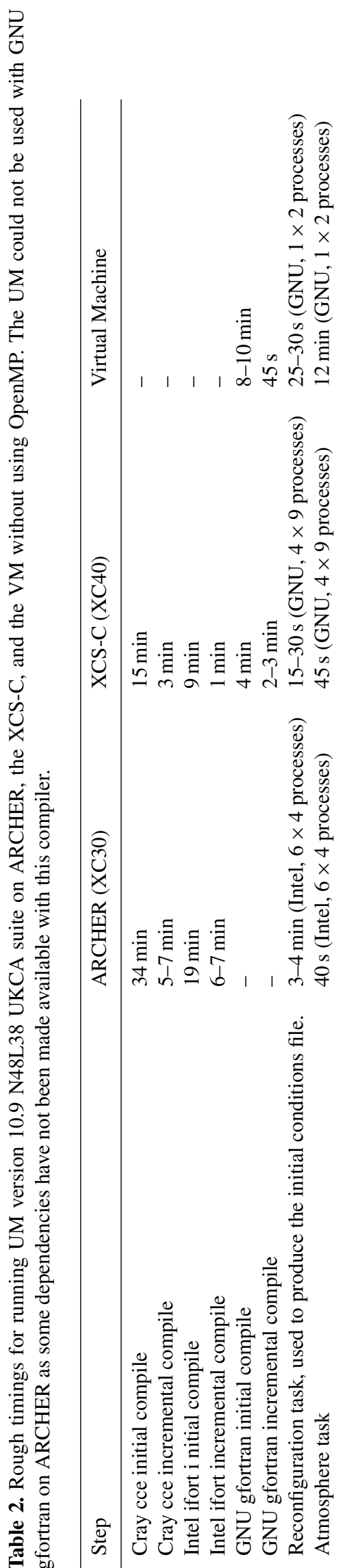

\section{Testing new model developments}

Each working copy of the UM includes a complete Rose suite that can be used to test the UM or install it to a fixed location. This suite is used with the "rose-stem" utility, which is used to run such test suites; the test suite itself is known as rose-stem (Whitehouse, 2018) and contains a number of different applications, known as "apps", which perform different tasks that can be automated. One of the functions of this suite is to install the UM itself, but it can also be used to run a series of known UM configurations and test them. As well as confirming that the tasks complete successfully, rose-stem is also able to compare the output from these configurations to already created standard output (also called "known good output", or KGO). This forms part of the standard UM development process at the Met Office and several partner sites, as each site has its own rose-stem configuration, including the Virtual Machine. When run with a new development, rosestem will enable a user to test that their code compiles and runs, and also whether it changes the results of known tests. Rose-stem is usually called from within a copy of the UM code; for installation this will be a copy of the UM trunk at a particular version (e.g. vn10.9), but for testing developments this will need to be a local copy containing the desired changes. It should be noted that if model output is no longer identical to the current KGO, this does not mean that the new output is not scientifically valid, just that the changes made to the code have also changed the results. Further testing and validation will be required to determine the scientific impact of these code changes.

At UM version 11.0 there are 109 different configurations of the UM tested at the Met Office with rose-stem, with more at partner sites, which test different science, compiler, and machine settings. On the virtual machine there are only 12 UM tests, with 3 of these being UKCA configurations. On the VM the UKCA rose-stem jobs provide the following checks:

1. Tests that new code compiles without errors when using both "safe" and "rigorous" compiler settings (see Table $3)$.

2. Tests that new code runs without errors when using both safe and rigorous compiler settings (see Table 3 ).

3. Tests whether new code changes results (this may be expected, depending on the change made).

4. Tests whether new code changes maintain results when using different processor decompositions.

5. Tests whether OpenMP parallelisation has been affected by new code changes, which then change results.

A listing of the UKCA rose-stem jobs on the VM can be found in Table 3. Each of these is constructed using a graph which links the different tasks of the job together by 
Table 3. UKCA rose-stem jobs available on the VM, showing the differences between Fortran compiler flags used for safe and rigorous compile options. C flags also differ. Both safe jobs point to the same KGO files.

\begin{tabular}{|c|c|c|c|c|}
\hline $\begin{array}{l}\text { Rose-stem job name } \\
\text { within the ukca group }\end{array}$ & $\begin{array}{l}\text { Compile } \\
\text { type }\end{array}$ & $\begin{array}{l}\text { GNU gfortran } \\
\text { compiler flags }\end{array}$ & $\begin{array}{r}\text { Number of UM } \\
\text { OpenMP threads }\end{array}$ & $\begin{array}{r}\text { Total VM memory } \\
\text { required (GB) }\end{array}$ \\
\hline vm_n48_ukca_eg_noomp & safe & -02 -Werror & 0 & 6 \\
\hline vm_n48_ukca_eg_omp_noios & safe & $\begin{array}{l}\text {-O2 -Werror } \\
\text {-fopenmp }\end{array}$ & 2 & 6 \\
\hline vm_n48_ukca_eg_omp_noios_comp_check & rigorous & $\begin{array}{l}\text {-oo-Wall } \\
\text {-ffpe-trap=invalid, zero } \\
\text {-fbounds-check } \\
\text {-Warray-bounds } \\
\text {-fcheck-array-temporaries } \\
\text {-finit-real=nan } \\
\text {-fimplicit-none } \\
\text {-fopenmp }\end{array}$ & 2 & 8 \\
\hline
\end{tabular}

Table 4. Approximate timings for different UKCA configurations on the VM at UM version 11.0. The compiler settings are listed in detail in Table 3.

\begin{tabular}{lrrr}
\hline Compiler settings & Safe & Safe & Rigorous \\
\hline Number of UM OpenMP threads & 0 & 2 & 2 \\
Approximate run-time on 2-core VM $(1 \times 2)$ (minutes) & 8 & 11 & 29 \\
Approximate run-time on 4-core VM $(1 \times 2)$ (minutes) & 8 & 4 & 17 \\
Approximate run-time on 4-core VM $(1 \times 4)$ (minutes) & 5 & 8 & 22 \\
Approximate run-time on 8-core VM $(1 \times 4)$ (minutes) & 5 & 3 & 14 \\
Approximate run-time on 8-core VM $(1 \times 8)$ (minutes) & 3 & 6 & 26 \\
Approximate run-time on 16-core VM $(1 \times 8)$ (minutes) & 3 & 3 & 22 \\
\hline
\end{tabular}

their dependencies. A simplified graph of these UKCA rosestem tests at UM version 11.0 is shown in Fig. 3. Additionally, equivalent GNU N48L38 tests to those on the VM have been implemented at the Met Office and are performed daily against the UM trunk. These test if any new code changes are likely to break the tests on the VM, effectively reducing the need for frequent VM rose-stem testing against the current and most recent UM code.

\subsection{Known good output tests}

In order to test against already produced known good output (KGO), this KGO must be produced and installed into a standard location. At the Met Office, this step is performed manually when new code is committed to the UM trunk, and so a growing and continual series of $\mathrm{KGO}$ is maintained and available; this allows any unexpected change of results to be detected as changes are made to the trunk and facilitates the testing of changes to the UM at or near the latest trunk revision. However, for the VM this maintenance, while possible, is labour intensive and usually unnecessary. The VM is not designed as a system that should be maintained through UM versions, it is designed to be used for simple code development against a single, stable UM release. This is also important due to other possible changes to the UM, Rose, and Cylc systems that would also be time-consuming to maintain. On the VM the KGO for each rose-stem job must be generated and installed when the UM is installed as it is machine dependent. This can be done by using the command

rose stem --group=ukca -S GENERATE_KGO=true

when running rose-stem on a copy of the UM trunk at the required version. The ukca term refers to the group of all the UKCA rose-stem jobs available on the VM (listed in Table 3$)$.

Once the KGO for the UKCA jobs is in place, it is then possible to run the rose-stem tests on a local copy of the UM containing a code change by using the command

rose stem --group=ukca

within the top-level directory of the local copy of the UM code. It is also possible to run separate jobs individually by replacing "ukca" above by the rose-stem job name (see Table 3). Once the various tasks are complete, rose-stem will automatically perform a bit-wise comparison between the UM output files generated by the reconfiguration and UM atmosphere steps and will highlight any differences between the KGO files and the files produced from the rose-stem jobs. Major science changes or bugfixes will often result in differences, but small changes or new schemes that are turned off should usually preserve the model evolution and hence the KGO tests should pass. If these KGO tests do not pass when they would be expected to do so, this may point to an error in the implementation. 


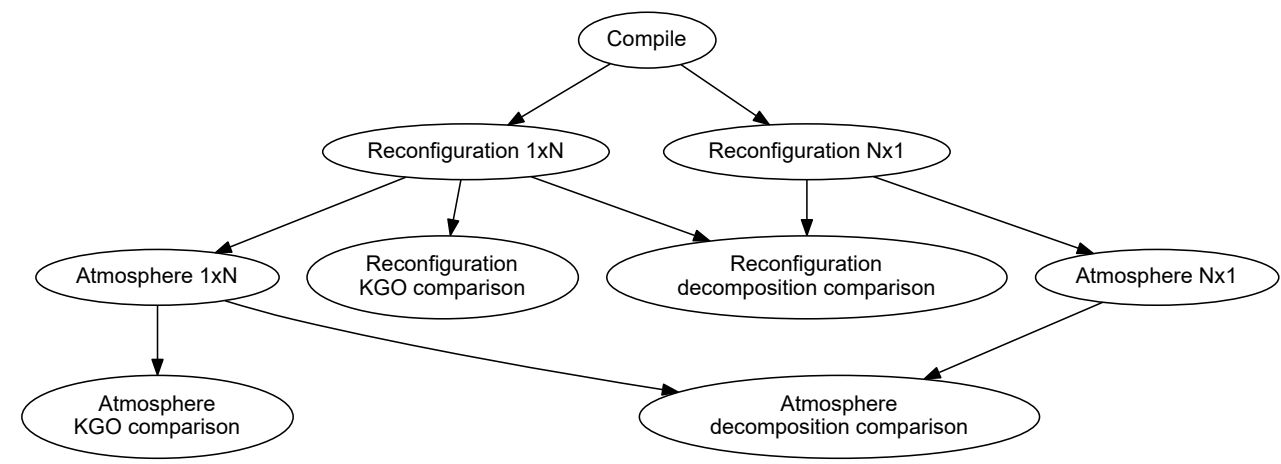

Figure 3. Simplified example rose-stem graph, showing the different tasks performed during a single job.

\subsection{Processor decomposition tests}

From UM version 11.0, when the flag $-S$ INTEGRATION_TESTING=true is passed to rose-stem, the UKCA jobs can be run in two different configurations to enable processor decomposition testing. Here the UM will use either $1 \times N$ processes or $N \times 1$ processes. By default, $N=2$, but this can be changed by adding $-\mathrm{S}$ MPI_TASKS=N on the call to rose-stem. The output from these two jobs is then compared in the same way as for the KGO comparison. By increasing the value of $N$ it is possible to reduce the run-time of these configurations, as seen in Table 4.

Scientifically, maintaining results when changing the number (or decomposition) of MPI processes is desirable as it allows for the resources to be changed during long climate runs, allowing for more or fewer processes to be used without affecting the model output. Technically, it helps test for code correctness. There may, for example, be bounds errors or race conditions that would never be encountered if only one decomposition is routinely tested, but that may show up if the run conditions are varied. By ensuring several decompositions give the same answer we reduce the risk of bugs in the code; something that changes answers in a second decomposition may cause a crash in third or produce nonsense.

Additionally, any impacts on OpenMP parallelisation can be tested by running job vm_n48_ukca_eg_omp_noios, as the KGO is produced using job vm_n48_ukca_eg_noomp and should be identical for both.

\section{Training new users}

When training new users of UM-UKCA how to use the model, we begin with the premise "what are the most common things that a new PhD student or researcher would need to know how to do in order to use UKCA?". When starting with UM-UKCA, often new users will wish to perform studies that will involve a combination of the following:
- creating or modifying emissions,

- adding new chemical species,

- adding new reactions,

- adding new deposition processes, and

- adding new diagnostics,

as well as needing to learn how to output and process UM and UKCA diagnostics, and also wanting to become more familiar with the model's user-interface.

We can in fact cover all these points by imagining two new chemical species, ALICE and BOB, and the chemical equation

$\mathrm{ALICE}+\mathrm{OH} \rightarrow \mathrm{BOB}+$ secondary organic species,

where secondary organic species (labelled as "Sec_Org" in the UKCA code) will condense to form secondary organic aerosol (Mann et al., 2010), ALICE is dry deposited, and $\mathrm{BOB}$ is wet deposited. The specifics of the emission field, reaction and deposition rates are unimportant, so long as they have reasonable values.

The steps to include the toy chemistry above to UMUKCA can then be broken down into the following tasks:

1. Add ALICE and BOB as transported tracers to the UM and UKCA.

2. Add surface emissions of ALICE, comprising of the following elements:

a. re-gridding of a provided $1^{\circ} \times 1^{\circ}$ dataset to $\mathrm{N} 48$ resolution;

b. saving this re-gridded emissions field to NetCDF with the correct metadata required by UKCA;

c. including this new NetCDF emissions file in the UKCA namelist within Rose.

3. Add the bimolecular Reaction (R1) to the UKCA StratTrop chemical mechanism. 
(a)

Emissions $1^{\circ} \times 1^{\circ}$

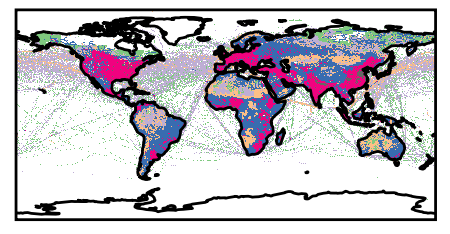

(c)

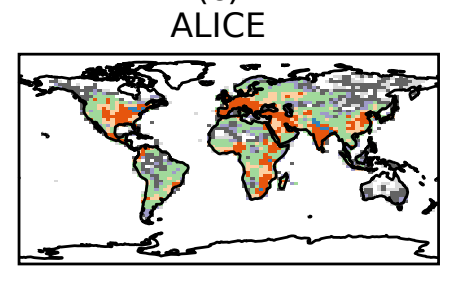

(e)

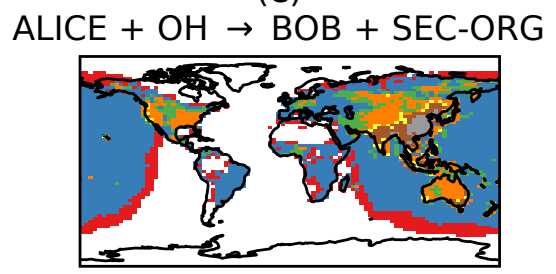

(g)

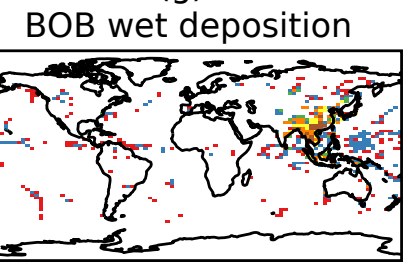

(b)

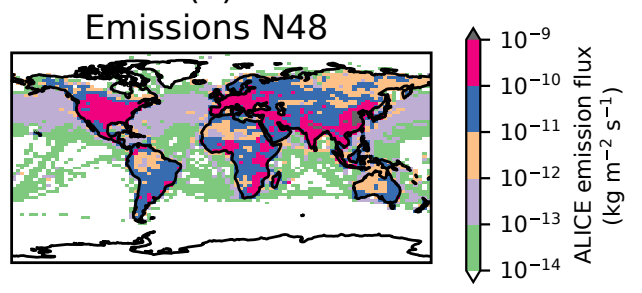

(d)

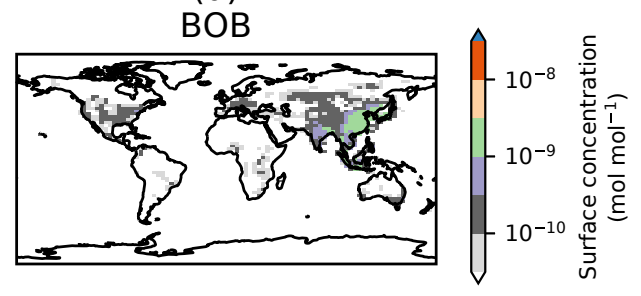

(f)

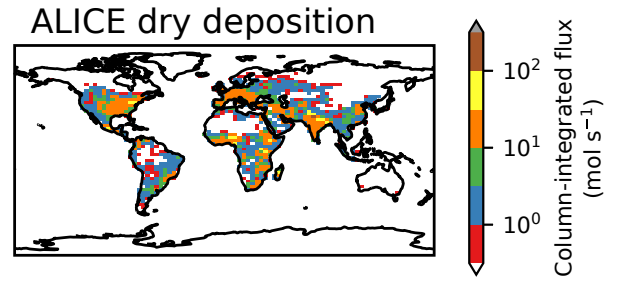

(h)

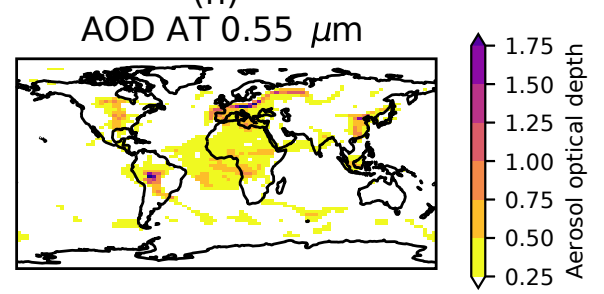

Figure 4. Showing output from the various UKCA tutorial tasks. (a) $1^{\circ} \times 1^{\circ}$ supplied September emissions. (b) Emissions re-gridded to N48. (c) $3 \mathrm{~h}$ mean ALICE surface mole fraction after the tutorials have been completed. (d) as for (c), but for BOB. (e) $3 \mathrm{~h}$ mean columnintegrated flux through Reaction (R1). (f) $3 \mathrm{~h}$ mean column-integrated ALICE dry deposition flux. (g) $3 \mathrm{~h}$ mean column-integrated BOB dry deposition flux. (h) $3 \mathrm{~h}$ mean total aerosol optical depth from GLOMAP-mode at $0.55 \mu \mathrm{m}$. ALICE and BOB were both initialised to $1.0 \times 10^{-12} \mathrm{~kg} \mathrm{~kg}^{-1}$.

4. Add the dry-deposition of ALICE to UKCA.

5. Add the wet-deposition of BOB to UKCA.

6. Add new diagnostic reaction fluxes to UM-UKCA to output the fluxes through steps introduced in 3,4 , and 5 above.

7. Process UM output to calculate aerosol optical depth.
To aid new users of UM-UKCA a series of online tutorials have been developed that go through the various (and complex) steps above required to make changes to the model. Detailed instructions are available for UM versions 8.2 (Abraham, 2013), 8.4 (Abraham and Mann, 2014), 10.4 (Abraham and Mann, 2016), and 10.9 (Abraham et al., 2017) using ARCHER. Additionally, at UM version 10.9 this UKCA training can be performed exclusively on the VM using a configuration based on the N48L38 model described in 
Sect. 4. Figure 4 shows typical output from the above tasks after they have been completed.

\section{Conclusions}

As can be seen in Table 2, the UM-UKCA configurations on the $\mathrm{VM}$ require longer runtimes than equivalent configurations on HPC systems. Using 2 MPI processes the N48L38 configuration would take at least $32 \mathrm{~h}$ to simulate one model month, although using a server as a host and adding more processes reduces this as seen in Table 4.

The decrease in horizontal resolution will be somewhat detrimental to the representation of the model dynamics and other physical or chemical processes (Stock et al., 2014; Strachan et al., 2013), although many UKCA studies have been performed using N48 resolution (Banerjee et al., 2014; Bednarz et al., 2016; Keeble et al., 2018; Nowack et al., 2015). However, the reduction in the number of vertical levels (see Fig. 2) is a significant issue as the chemistry scheme used, StratTrop, is designed to simulate both stratospheric and tropospheric chemistry, and without a full model stratosphere it is computationally inefficient to include all the reactions in this scheme. Also, due to this low top, the look-up table photolysis scheme, used in the region above the Fast-JX photolysis scheme (Telford et al., 2013), will not be called.

The chemistry scheme used in HadGEM2-ES (O'Connor et al., 2014) would be appropriate for this level structure, but this would then not test the equivalent settings to the N96L85 GA7+StratTrop configuration, and so the usefulness of the tests listed in Table 4 would be reduced. By keeping as many settings as possible the same between these configurations it allows the VM tests to be traceable to N96L85 tests performed on the Met Office systems.

While the VM is ideal for initial development and testing of new code, once long science integrations need to be done it is necessary to switch to a standard N96L85 climate configuration on a HPC system. Simulations of around 20-years in length are usually required to see if any new science introduces a significant change to stratospheric composition, and these are not feasible to be performed on the VM. However, the VM could be used for stand-alone scientific studies making use of the UKCA Box Model (Esentürk et al., 2018) or UKCA called from the Single Column Model, although further work would be required to allow these configurations to work on the VM.

While the toy chemistry discussed in Sect. 6 does not cover all reaction types covered and may be considered simpler than most changes new users may wish to make, it is sufficiently detailed enough to give users experience with many different parts of the UKCA code. While using the VM will give users experience of using and editing the UM's Rose graphical user interface, it will not provide experience in using UM-UKCA on a HPC system. However, this is also an advantage, as it means that it is possible to gain experience in using and developing UM-UKCA before committing supercomputer resources.

Despite these limitations, the VM is an easy-to-use system that is available to all current and potential users, and creates a consistent environment for model development, testing, and training. This system is complementary to, rather than being a replacement for, using UM-UKCA on HPC systems.

Code availability. The Met Office Virtual Machine can be obtained from https://github.com/metomi/metomi-vms (Matthews et al., 2018). Due to intellectual property right restrictions, we cannot provide either the source code or documentation papers for the UM.

Obtaining the UM. The Met Office Unified Model is available for use under licence. The functionality discussed here is fully available in the UM trunk from version 11.0, with detailed instructions on how to install the UM on the VM provided by UMDP X10 (Cresswell, 2018), and the UM version 10.9 UKCA Tutorials are described in Abraham et al. (2017). A number of research organisations and national meteorological services use the UM in collaboration with the Met Office to undertake basic atmospheric process research, produce forecasts, develop the UM code and build and evaluate Earth system models. For further information on how to apply for a licence; see http://www.metoffice.gov.uk/research/ modelling-systems/unified-model (last access: 7 May 2018).

Author contributions. NLA wrote the paper with input from all authors. The VM was developed by DM and the UM ported to it by PC. NLA ported UKCA to the VM with support from MD and PC. NLA implemented the rose-stem tests and KGO generation on the VM with support and advice from PC, SC, SteW, and StuW. NLA developed the UKCA tutorials with advice from ATA.

Competing interests. The authors declare that they have no conflict of interest.

Acknowledgements. This work used the ARCHER UK National Supercomputing Service (http://www.archer.ac.uk, last access: 7 May 2018). This work used Monsoon2, a collaborative highperformance computing facility funded by the Met Office and the Natural Environment Research Council. This work used the NEXCS High Performance Computing facility funded by the Natural Environment Research Council and delivered by the Met Office.

UKCA training has been supported by the NERC ACITIES atmospheric chemistry modelling network, grant no. NE/K001280/1 and NERC Advanced Training Short Courses scheme, grant nos. NE/M006220/1, NE/N000129/1, NE/N019091/1, and NE/P020089/1. We would like to thank the UM Systems Team at the Met Office. NLA would like to thank John Pyle, Bryan Lawrence, and NCAS Computational Modelling Services for supporting this work. The work of MD was supported by the Met Office Hadley Centre Climate Programme funded by BEIS and Defra. 
Edited by: David Ham

Reviewed by: two anonymous referees

\section{References}

Abraham, N. L.: UKCA \& UMUI Tutorials for UM8.2, Online Learning Materials, https://doi.org/10.17863/CAM.22149, available at: http://www.ukca.ac.uk/wiki/index.php/UKCA_\&_ UMUI_Tutorials (last access: 26 March 2018), 2013.

Abraham, N. L. and Mann, G. W.: UKCA Chemistry and Aerosol Tutorials for UM8.4, Online Learning Materials, https://doi.org/10.17863/CAM.22151, available at: http://www.ukca.ac.uk/wiki/index.php/UKCA_Chemistry_and_ Aerosol_Tutorials (last access: 26 March 2018), 2014.

Abraham, N. L. and Mann, G. W.: UKCA Chemistry and Aerosol Tutorials at vn10.4 using Rose \& Cylc, Online Learning Materials, https://doi.org/10.17863/CAM.22152, available at: http://www.ukca.ac.uk/wiki/index.php/UKCA_Chemistry_and_ Aerosol_Tutorials_at_vn10.4 (last access: 26 March 2018), 2016.

Abraham, N. L., Bellouin, N., and Schmidt, A.: UKCA Chemistry and Aerosol Tutorials at vn10.9 using Rose \& Cylc, Online Learning Materials, https://doi.org/10.17863/CAM.22153, available at: http://www.ukca.ac.uk/wiki/index.php/UKCA_ Chemistry_and_Aerosol_Tutorials_at_vn10.9 (last access: 26 March 2018), 2017.

Abraham, N. L., Archibald, A. T., Bellouin, N., Boucher, O., Braesicke, P., Bushell, A., Carslaw, K., Collins, B., Dalvi, M., Dennison, F., Emmerson, K., Folberth, G., Haywood, J., Hewitt, A., Johnson, C., Kipling, Z., Macintyre, H., Mann, G., Telford, P., Merikanto, J., Morgenstern, O., O’Connor, F., Ordonez, C., Osprey, S., Pringle, K., Pyle, J., Rae, J., Reddington, C., Savage, N., Sellar, A., Spracklen, D., Stier, P., West, R., Mulcahy, J., Woodward, S., Boutle, I., and Woodhouse, M. T.: UMDP 084: United Kingdom Chemistry and Aerosol (UKCA) Technical Description, available at: https://code.metoffice.gov.uk/doc/um/vn11.0/ papers/umdp_084.pdf, last access: 23 February 2018.

Banerjee, A., Archibald, A. T., Maycock, A. C., Telford, P., Abraham, N. L., Yang, X., Braesicke, P., and Pyle, J. A.: Lightning $\mathrm{NO}_{\mathrm{x}}$, a key chemistry-climate interaction: impacts of future climate change and consequences for tropospheric oxidising capacity, Atmos. Chem. Phys., 14, 9871-9881, https://doi.org/10.5194/acp-14-9871-2014, 2014.

Bednarz, E. M., Maycock, A. C., Abraham, N. L., Braesicke, P., Dessens, O., and Pyle, J. A.: Future Arctic ozone recovery: the importance of chemistry and dynamics, Atmos. Chem. Phys., 16, 12159-12176, https://doi.org/10.5194/acp-16-121592016, 2016.

Collins, W. J., Bellouin, N., Doutriaux-Boucher, M., Gedney, N., Halloran, P., Hinton, T., Hughes, J., Jones, C. D., Joshi, M., Liddicoat, S., Martin, G., O'Connor, F., Rae, J., Senior, C., Sitch, S., Totterdell, I., Wiltshire, A., and Woodward, S.: Development and evaluation of an Earth-System model - HadGEM2, Geosci. Model Dev., 4, 1051-1075, https://doi.org/10.5194/gmd-4-10512011, 2011.

Collins, W. J., Lamarque, J.-F., Schulz, M., Boucher, O., Eyring, V., Hegglin, M. I., Maycock, A., Myhre, G., Prather, M., Shindell, D., and Smith, S. J.: AerChemMIP: quantifying the effects of chemistry and aerosols in CMIP6, Geosci. Model Dev., 10, 585607, https://doi.org/10.5194/gmd-10-585-2017, 2017.

Cresswell, P.: Unified Model Documentation Paper X10: Unified Model Virtual Machine Guide, available at: https://code. metoffice.gov.uk/doc/um/vn11.0/papers/umdp_X10.pdf, last access: 6 March 2018.

Cullen, M. J. P.: The unified forecast/climate model, Meteorol. Mag., 122, 81-94, 1993.

Esentürk, E., Abraham, N. L., Archer-Nicholls, S., Mitsakou, C., Griffiths, P., Archibald, A., and Pyle, J.: Quasi-Newton methods for atmospheric chemistry simulations: implementation in UKCA UM vn10.8, Geosci. Model Dev., 11, 3089-3108, https://doi.org/10.5194/gmd-11-3089-2018, 2018.

Eyring, V., Bony, S., Meehl, G. A., Senior, C. A., Stevens, B., Stouffer, R. J., and Taylor, K. E.: Overview of the Coupled Model Intercomparison Project Phase 6 (CMIP6) experimental design and organization, Geosci. Model Dev., 9, 1937-1958, https://doi.org/10.5194/gmd-9-1937-2016, 2016.

Ferracci, V., Heimann, I., Abraham, N. L., Pyle, J. A., and Archibald, A. T.: Global modelling of the total $\mathrm{OH}$ reactivity: investigations on the "missing" $\mathrm{OH}$ sink and its atmospheric implications, Atmos. Chem. Phys., 18, 7109-7129, https://doi.org/10.5194/acp-18-7109-2018, 2018.

Finney, D. L., Doherty, R. M., Wild, O., and Abraham, N. L.: The impact of lightning on tropospheric ozone chemistry using a new global lightning parametrisation, Atmos. Chem. Phys., 16, 75077522, https://doi.org/10.5194/acp-16-7507-2016, 2016.

Hacker, J. P., Exby, J., Gill, D., Jimenez, I., Maltzahn, C., See, T., Mullendore, G., and Fossell, K.: A Containerized Mesoscale Model and Analysis Toolkit to Accelerate Classroom Learning, Collaborative Research, and Uncertainty Quantification, B. Am. Meteorol. Soc., 98, 1129-1138, https://doi.org/10.1175/BAMSD-15-00255.1, 2017.

Hardiman, S. C., Butchart, N., O'Connor, F. M., and Rumbold, S. T.: The Met Office HadGEM3-ES chemistryclimate model: evaluation of stratospheric dynamics and its impact on ozone, Geosci. Model Dev., 10, 1209-1232, https://doi.org/10.5194/gmd-10-1209-2017, 2017.

HashiCorp: Vagrant, available at: https://www.vagrantup.com/, last access: 27 March 2018.

Keeble, J., Brown, H., Abraham, N. L., Harris, N. R. P., and Pyle, J. A.: On ozone trend detection: using coupled chemistryclimate simulations to investigate early signs of total column ozone recovery, Atmos. Chem. Phys., 18, 7625-7637, https://doi.org/10.5194/acp-18-7625-2018, 2018.

Lee, H., Goodman, A., McGibbney, L., Waliser, D., Kim, J., Loikith, P., Gibson, P., and Massoud, E.: Regional Climate Model Evaluation System powered by Apache Open Climate Workbench v1.3.0: an enabling tool for facilitating regional climate studies, Geosci. Model Dev. Discuss., https://doi.org/10.5194/gmd-2018-113, in review, 2018.

Mann, G. W., Carslaw, K. S., Spracklen, D. V., Ridley, D. A., Manktelow, P. T., Chipperfield, M. P., Pickering, S. J., and Johnson, C. E.: Description and evaluation of GLOMAP-mode: a modal global aerosol microphysics model for the UKCA composition-climate model, Geosci. Model Dev., 3, 519-551, https://doi.org/10.5194/gmd-3-519-2010, 2010.

Matthews, D., Cresswell, P., Abraham, L., Whitehouse, S., and Fitzpatrick, B.: Vagrant virtual machines with 
$\mathrm{FCM}+$ Rose + Cylc installed, GitHub Repository, https://doi.org/10.5281/zenodo.1341042, available at: https://github.com/metomi/metomi-vms, last access: $7 \mathrm{Au}-$ gust 2018.

Morgenstern, O., Braesicke, P., O'Connor, F. M., Bushell, A. C., Johnson, C. E., Osprey, S. M., and Pyle, J. A.: Evaluation of the new UKCA climate-composition model Part 1: The stratosphere, Geosci. Model Dev., 2, 43-57, https://doi.org/10.5194/gmd-2-43-2009, 2009.

Morgenstern, O., Hegglin, M. I., Rozanov, E., O’Connor, F. M., Abraham, N. L., Akiyoshi, H., Archibald, A. T., Bekki, S., Butchart, N., Chipperfield, M. P., Deushi, M., Dhomse, S. S., Garcia, R. R., Hardiman, S. C., Horowitz, L. W., Jöckel, P., Josse, B., Kinnison, D., Lin, M., Mancini, E., Manyin, M. E., Marchand, M., Marécal, V., Michou, M., Oman, L. D., Pitari, G., Plummer, D. A., Revell, L. E., Saint-Martin, D., Schofield, R., Stenke, A., Stone, K., Sudo, K., Tanaka, T. Y., Tilmes, S., Yamashita, Y., Yoshida, K., and Zeng, G.: Review of the global models used within phase 1 of the Chemistry-Climate Model Initiative (CCMI), Geosci. Model Dev., 10, 639-671, https://doi.org/10.5194/gmd-10-639-2017, 2017.

Nowack, P. J., Luke Abraham, N., Maycock, A. C., Braesicke, P., Gregory, J. M., Joshi, M. M., Osprey, A., and Pyle, J. A.: A large ozone-circulation feedback and its implications for global warming assessments, Nat. Clim. Change., 5, 41-45, https://doi.org/10.1038/nclimate2451, 2015.

O’Connor, F. M., Johnson, C. E., Morgenstern, O., Abraham, N. L., Braesicke, P., Dalvi, M., Folberth, G. A., Sanderson, M. G., Telford, P. J., Voulgarakis, A., Young, P. J., Zeng, G., Collins, W. J., and Pyle, J. A.: Evaluation of the new UKCA climatecomposition model - Part 2: The Troposphere, Geosci. Model Dev., 7, 41-91, https://doi.org/10.5194/gmd-7-41-2014, 2014.

Oliver, H. J., Shin, M., Fitzpatrick, B., Clark, A., Sanders, O., Valters, D., Smout-Day, K., Bartholomew, S., Challuri, P., Matthews, D., Wales, S., Trzeciak, T., Kinoshita, B. P., Hatcher, R., Osprey, A., Reinecke, A., Williams, J., Jontyq, Coleman, T., Dix, M., and Pulo, K.: Cylc - a workflow engine, GitHub Repository, https://doi.org/10.5281/zenodo.1208732, available at: http: //cylc.github.io/cylc/, last access: 27 March 2018.

Oracle: VirtualBox, available at: https://www.virtualbox.org/, last access: 27 March 2018.

Shin, M., Fitzpatrick, B., Matthews, D., Whitehouse, S., Cresswell, P., Clark, A., Oxley, S., Dix, M., Sharp, R., and Smout-Day, K.: FCM: Flexible Configuration Management, GitHub Repository, https://doi.org/10.5281/zenodo.1001104, available at: http: //metomi.github.io/fcm/doc/ (last access: 27 March 2018), 2017.

Shin, M., Fitzpatrick, B., Clark, A., Sanders, O., Smout-Day, K., Whitehouse, S., Wardle, S., Matthews, D., Oxley, S., Valters, D., Mancell, J., Shepherd, H., Bartholomew, S., Oliver, H. J., Wales, S., Seddon, J., Osprey, A., Dix, M., and Sharp, R.: Rose: a framework for managing and running meteorological suites, GitHub Repository, https://doi.org/10.5281/zenodo.1168021, available at: http://metomi.github.io/rose/doc/rose.html, last access: 27 March 2018.
Skamarock, C., Klemp, B., Dudhia, J., Gill, O., Barker, D., Duda, G., Huang, X., Wang, W., and Powers, G.: A Description of the Advanced Research WRF Version 3, https://doi.org/10.5065/D68S4MVH, 2008.

Stock, Z. S., Russo, M. R., and Pyle, J. A.: Representing ozone extremes in European megacities: the importance of resolution in a global chemistry climate model, Atmos. Chem. Phys., 14, 3899-3912, https://doi.org/10.5194/acp-14-3899-2014, 2014.

Strachan, J., Vidale, P. L., Hodges, K., Roberts, M., and Demory, M.-E.: Investigating global tropical cyclone activity with a hierarchy of AGCMs: the role of model resolution, J. Climate, 26, 133-152, 2013.

Telford, P. J., Abraham, N. L., Archibald, A. T., Braesicke, P., Dalvi, M., Morgenstern, O., O'Connor, F. M., Richards, N. A. D., and Pyle, J. A.: Implementation of the Fast-JX Photolysis scheme (v6.4) into the UKCA component of the MetUM chemistry-climate model (v7.3), Geosci. Model Dev., 6, 161177, https://doi.org/10.5194/gmd-6-161-2013, 2013.

UK Met Office: Iris: A Python library for Meteorology and Climatology, available at: http://scitools.org.uk/iris/index.html, last accessed 27 March 2018a.

UK Met Office: Met Office Science Repository Service, available at: https://code.metoffice.gov.uk/trac/home/, last access: 10 April 2018b.

Walters, D., Boutle, I., Brooks, M., Melvin, T., Stratton, R., Vosper, S., Wells, H., Williams, K., Wood, N., Allen, T., Bushell, A., Copsey, D., Earnshaw, P., Edwards, J., Gross, M., Hardiman, S., Harris, C., Heming, J., Klingaman, N., Levine, R., Manners, J., Martin, G., Milton, S., Mittermaier, M., Morcrette, C., Riddick, T., Roberts, M., Sanchez, C., Selwood, P., Stirling, A., Smith, C., Suri, D., Tennant, W., Vidale, P. L., Wilkinson, J., Willett, M., Woolnough, S., and Xavier, P.: The Met Office Unified Model Global Atmosphere 6.0/6.1 and JULES Global Land 6.0/6.1 configurations, Geosci. Model Dev., 10, 1487-1520, https://doi.org/10.5194/gmd-10-1487-2017, 2017a.

Walters, D., Baran, A., Boutle, I., Brooks, M., Earnshaw, P., Edwards, J., Furtado, K., Hill, P., Lock, A., Manners, J., Morcrette, C., Mulcahy, J., Sanchez, C., Smith, C., Stratton, R., Tennant, W., Tomassini, L., Van Weverberg, K., Vosper, S., Willett, M., Browse, J., Bushell, A., Dalvi, M., Essery, R., Gedney, N., Hardiman, S., Johnson, B., Johnson, C., Jones, A., Mann, G., Milton, S., Rumbold, H., Sellar, A., Ujiie, M., Whitall, M., Williams, K., and Zerroukat, M.: The Met Office Unified Model Global Atmosphere 7.0/7.1 and JULES Global Land 7.0 configurations, Geosci. Model Dev. Discuss., https://doi.org/10.5194/gmd-2017291, in review, 2017b.

Whitehouse, S.: Unified Model Documentation Paper X09: The UM rose-stem Suite for External Users, available at: https://code. metoffice.gov.uk/doc/um/vn11.0/papers/umdp_X09.pdf, last access: 16 February 2018. 